\title{
SWOT Analysis of a Didactic Program in Dietetics: Results from Focus Group Research
}

\author{
David Edens (Corresponding Author) \\ Department of Nutrition and Food Science, Cal Poly Pomona \\ 3801 West Temple Ave, Pomona, CA 91738, United States \\ Bonny Burns-Whitmore \\ Department of Nutrition and Food Science, Cal Poly Pomona \\ 3801 West Temple Ave, Pomona, CA 91738, United States
}

Received: October 17, 2021 Accepted: November 18, 2021 Published: November 27, 2021

doi:10.5296/jet.v9i1.18018

URL: https://doi.org/10.5296/jet.v9i1.18018

\begin{abstract}
This study utilized focus group research to understand the experiences of students in a Didactic Program in Dietetics (DPD) at a large, public university. Students participating in the focus group reflected on and discussed the strengths, weakness, opportunities, and threats of the program. The participants stated that faculty support, hands-on learning, and opportunities to participate in clubs were strengths of the program. Students would like more opportunity to do research with faculty. They also indicated that there are program weaknesses such as access to common space, limits in course availability, roadblocks in curriculum, and limited access to necessary tools. Program opportunities, such as the upcoming accreditation visit, will express the student's concerns and therefore focus administration's attention on much needed financial support for the program. Although not a specific threat, changes in the credentialing for Registered Dietitian Nutritionists were also discussed by the students. Data were collected in preparation for an accreditation visit. However, the results can be used to advise department and university administrators about what items make students successful in their programs.
\end{abstract}

Keywords: SWOT analysis, focus group, nutrition training, accreditation

\section{Introduction and Background}

Didactic Programs in Dietetics (DPD) in the United States are accredited through the Accrediting Council for Education in Nutrition and Dietetics (ACEND), the accreditation 
branch of the Academy of Nutrition and Dietetics (Accreditation Council for Education in Nutrition and Dietetics [ACEND], 2018). The previous accreditation visit was in 2012 and the program was certified for a seven-year period. This study reviewed the experiences of students in a DPD program at a large university in [region, State]. The purpose of the study was to collect focus group data from DPD students not only for input into program improvement, analysis, and resource allocation, but for use in the program's ACEND self-study 2019-2020 reaccreditation process.

\subsection{Framework}

Student success and student experiences in college are an important measure that university administrators and accreditors review on a regular basis (Arnold et al., 2019; Brittingham et al., 2008). The goal is to provide an environment for the students to learn and thrive while meeting specific learning outcomes, especially for those programs that are credentialed through a professional society or organization such as ACEND (Accreditation Council for Education in Nutrition and Dietetics [ACEND], 2018).

\subsection{Student Success}

Student success has many definitions. Retention, persistence, grade point average, and many other factors are often listed as measures of success (Astin, 1993; Kuh et al., 2006; Kuh et al., 2005). More recently, items such as student satisfaction (Edens, 2012; Elliot \& Shin, 2002; Wiers-Jenssen et al., 2002), motivation (Pintrich, 2004; Schunk, 1991; Svinicki, 2004), and student self-efficacy (Bandura, 1993; Chemers et al., 2001; Pajares, 1996; Schunk, 1991) have become areas of productive research. Additionally, the topic of diversity in education and the link to student success has been explored, within the field of dietetics, student retention, and nutrition training (Olivares et al., 2015; Wynn et al., 2017).

\subsection{Experiential Learning}

Experiential learning is an another concept that relates to student success (Barr et al., 2002). Experiential learning includes students engaging in practical experiences in labs, activities, and service learning. DPD programs often incorporate aspects of service learning, a type of experiential learning, to support student learning and professional preparation. Experiential learning is especially important to the university as the university motto is "Learn by Doing". In this case, experiential learning, including labs, activities and service learning, is a substantial component of the university student success model.

\subsection{Accreditation Process}

As this project was conducted as part of a cyclical reaccreditation review, it is important to review accreditation and its purpose. The most important process for accreditation is quality assurance. Lubinescu, Raticliff, and Gaffney (2001) provide several purposes for both academic and programmatic accreditation. The authors defined the purpose of accreditation as an opportunity to:

- $\quad$ Foster excellence through the development of criteria and guidelines for assessing effectiveness 
- $\quad$ Encourage improvement through ongoing self-study and planning

- $\quad$ Ensure external constituents that a program has clearly defined goals and appropriate objectives, maintains faculty and facilities to attain them, demonstrates it is accomplishing them, and has the prospect for continuing to do so

- $\quad$ Provides advice and counsel to new and established programs in the accrediting process

- $\quad$ Ensures that programs receive sufficient support and are free from external influence that may impede their effectiveness and their freedom of inquiry.

In the case of dietetic and nutrition education and professional preparation, ACEND accredits dietetic programs for many of the same reasons. Most notably, the ACEND accrediting process assures the quality of nutrition and dietetics education for preparing students in future careers as Registered Dietitian Nutritionists and Nutrition and Dietetics Technicians, Registered (ACEND, 2018).

\subsection{Assessment}

One major component of accreditation is the verification that students are meeting certain standards and learning outcomes and ultimately succeeding in college. Assessment is a means of collecting data on student success and learning, reviewing such data, and developing programmatic changes to improve student learning (Massa \& Kasimatis, 2017).

\subsection{Research Question}

This qualitative study was conducted to inform the faculty and staff of the department about the student experiences in the DPD program. Therefore, the research question that guided this study was, "What are the student's impressions of the strengths, weaknesses, opportunities, and threats to the current DPD program at the university?"

\section{Methodology}

This qualitative study was conducted at a large, public university in California. Prior to the start of the study, the researchers obtained IRB approval from the university (protocol \#19-111). The focus group was conducted to collect student input on their feelings about the Didactic Program in Dietetics at the university. As a method, focus groups allow the participants to freely express their feelings about the subject being discussed with periodic prompts from a facilitator (Creswell, 2005, 2007).

The participants were recruited during the Fall semester through department emails and announcement at the student club meetings. As this study focused on the experiences of students in the DPD program, only students in the Didactic Program in Dietetics at the university were recruited. At the university, there are approximately 270 students enrolled in DPD program (Cal Poly Pomona [CPP], 2020). Eight students participated in the focus group session. This number represents $3 \%$ of the total enrolled in the program. However, the typical size for a focus group is between 7 and 12 participants (Creswell, 2007). All the participants were female with six holding senior standing and the remaining two holding junior standing. 
Within the study DPD program and nationally, the profession is primarily female (CPP, 2020; Pollard et al., 2007). Although all levels of students were recruited for the study, students with junior or senior standing are the best as these students have experienced the core of the DPD curriculum, and first- and second-year students are often still in the process of completing general education and pre-requisite requirements prior to starting the DPD curriculum. The institution is considered a commuter school and serves many non-traditional students. For example, the typical age of students enrolled in the department is 23.20 and the age range for the participants was between 20 to 44, with the average being 27 (CPP, 2020). As the study university is a Hispanic-Serving Institution, the ethnic diversity of the focus group was similar to the DPD program with the majority (62\%) being Latinx as compared to 56\% Latinx for the department and 51\% Latinx for the university as a whole (CPP, 2020). Seventy-five percent of the focus group were senior standing (90 or more units completed). The entire group of participants identified as female, which is somewhat similar to the program where the majority (76\%) of the DPD students identify as female (CPP, 2020). The group that may be underrepresented were Asians, as 19\% of the DPD students are Asian (CPP, 2020).

The Focus Group technique was chosen for this study to obtain student input. Focus Groups are one means of collecting qualitative data for applications such as academic assessments. The focus group methodology has been used in many research settings including the social sciences (Parker \& Tritter, 2006). Typically, focus groups are organized with a small group in a discussion setting led by a facilitator who asks questions and guides the overall discussion (Creswell, 2007). Additionally, the facilitator may add follow-up lines of questioning to gain deeper insight regarding the topic being discussed by the group. Once the group session is complete, the collected data is evaluated for common themes. These themes are analyzed to form the basis for the findings in this style of qualitative research. Focus group research has been conducted in the nutrition field to gain insights regarding student experiences (Kessler \& Burns-Whitmore, 2011; Kessler et al., 2009; Kessler et al., 2010; Kessler et al., 2013), and the data was used to develop program goals, objectives, and improvements, as well as student retention and mentoring.

After signing an informed consent, the participants were led through a focus group session to discuss the strengths, weaknesses, opportunities, and threats concerning the DPD program at the university. The questions are presented in Table 1. A single focus group session was conducted during the Fall semester in one of the DPD program's lab rooms and lasted for the scheduled 60 minutes. During the focus group, the participants were video-taped, and the moderator took notes. Following the session, the video was transcribed with the aid of trint.com software. After transcription, the data, including notes, was re-read and compared for the purpose of coding (Creswell, 2007). Open, deductive coding was used to manually code the data. As this focus group was framed to collect data using a SWOT analysis, the themes and results were organized around the four major groupings in SWOT, strengths, weaknesses, opportunities, and threats (Helms Marilyn \& Nixon, 2010). 


\subsection{Researchers}

The researchers in this study are faculty members within the DPD program at the study university. Both researchers are invested in the success of the students in the program and want both the students and the program to succeed. One researcher is also currently training to become an ACEND accreditation reviewer in the future. The researchers recognize the need to remain unbiased in this process and the need to hear the messages from the student participants. The goal for the researchers is to ultimately improve the DPD program for future students.

Table 1. Focus Group Questions

\begin{tabular}{|c|c|}
\hline Area of Focus & Questions \\
\hline \multirow[t]{4}{*}{ Strengths } & - What does the Dietetics Program do well? \\
\hline & - What are our best resources? \\
\hline & - What do other people see as the program's strengths? \\
\hline & $\begin{array}{l}\text { - What would you want to boast/brag about to someone who knows nothing about our } \\
\text { program? }\end{array}$ \\
\hline \multirow[t]{6}{*}{ Weaknesses } & - What can be improved? \\
\hline & - What is done poorly? \\
\hline & - What can be done better/effectively/efficiently? \\
\hline & - What is the Dietetics Program NOT doing that you feel it should be doing? \\
\hline & $\begin{array}{l}\text { - If you could change one thing that would help this department function more effectively, } \\
\text { what would you change? }\end{array}$ \\
\hline & - If you could change one thing about the program, what would you change? \\
\hline \multirow[t]{3}{*}{ Opportunities } & - What are the good opportunities facing the program? \\
\hline & - What are the interesting trends you are aware of? \\
\hline & $\begin{array}{l}\text { - Are there opportunities that the department should focus on, that you think could be } \\
\text { implemented? }\end{array}$ \\
\hline \multirow[t]{5}{*}{ Threats } & - What are the perceived threats regarding the program? \\
\hline & - What obstacles do you face? \\
\hline & - What is our competition doing that we are not doing? \\
\hline & - Could any of the program/department/college/university weaknesses seriously threaten the \\
\hline & Dietetics Program? \\
\hline Overall & $\begin{array}{l}\text { - Has your experience in the major been good or bad or a combination of both? Please share } \\
\text { your experiences. }\end{array}$ \\
\hline
\end{tabular}




\section{Results and Discussion}

\subsection{Strengths of the Program}

In general, the students were satisfied with their experiences in the DPD program. A major theme that was discussed was the support the students receive from professors, advisors and the student clubs such as the nutrition student and the honor society. The students felt that such support was a major strength of the program. Additionally, the students were proud to be part of the DPD program at the university. As the students continued discussing the strengths of the program, one student stated that it is "cool to talk about what I am passionate about." Students on the panel commented on the many opportunities to get involved with other students and the faculty in the department. Another participant commented that "I never imagined I would be so involved. I am almost in tears about missing school.”

An additional theme emerged when discussing strengths. The students liked the many hands-on opportunities that exist on campus. There are opportunities to be involved with real world applications such as cooking in quantity for fundraisers and special events, community nutrition services, counseling, and participation in research projects with faculty and graduate students.

Finally, the in-class experience was noted as a strength of the program. As previously stated, the students spoke highly of the faculty, both tenure track and lecturers. The students talked about the curriculum and their classroom experiences. One student noted, that they (the students) are held to a high standard. One student said "the textbook is the minimum. We (the students) are encouraged to go above and beyond" for their learning. The group added that they liked their relationships with the faculty. They found the faculty approachable and that the faculty are there to support the students and help them both in- and out-of-the classroom. Importantly, faculty-student interaction is a major factor in overall student success, both in and outside of the classroom (Kuh et al., 2006; Kuh et al., 2005; Umbach \& Wawrzynski, 2005). These comments support the development of faculty-student opportunities. Faculty and administrators can develop programs such as undergraduate research and career mentoring to enhance the relationship between faculty and students beyond the classroom environment.

\subsection{Weakness and Challenges}

There were challenges identified by the students on the focus group. Space is an issue in the college. The students expressed that it is tough for them to find space or rooms to study together and collaborate. The students talked about how a neighboring college, of which the DPD program shares space with, has study areas and a student lounge. Having a space for study and collaboration may benefit the students in terms of study time, group projects, and general moral and satisfaction by offering a central gathering space for the program. The students also offered a suggestion to allow use of some of the rooms or facilities on weekends to support collaborative learning. This suggestion could be especially beneficial as the campus is primarily a commuter campus. Having a space to work and gather may allow more opportunities for interaction while the students are on campus. Interaction with both other 
students and faculty fosters student success and satisfaction (Astin, 1993; Kuh et al., 2005).

Access to technology in the college's computer lab was also identified as a weakness. The computer lab is the only place where the nutrition/diet analyzing software is available to students. There are 24 licenses for use in the lab. With additional courses in the college using the lab for teaching, there are fewer open hours for the students to use the software. Overall, the students expressed the need for more access or additional software tools to complete their projects.

Additionally, the curriculum itself is was identified as a challenge. Most notable was the students' comments the chemistry courses in the curriculum. They noted that chemistry, especially organic chemistry, was often hard for them. If a student does not successfully pass the introductory chemistry series, organic chemistry, and then biochemistry, they cannot proceed to the metabolism courses and medical nutrition therapy series. Not being successful in chemistry delays student's graduation and eventual dietetic internship. The student group suggested that the department develop a DPD study group for chemistry to support student learning. One of the participants asked why organic chemistry was even needed for the major. They did understand the link to biochemistry but felt that organic chemistry was not as important. However, one student stated that the chemistry series made her grow as a student. She said, chemistry "...made her work and figure it out. It changed my mind from a fixed mindset to a growth mindset." She expressed pride in completing the chemistry portion of the curriculum. Challenging the student and setting high standards promotes student learning on a deep level (Kuh et al., 2006). Additionally, challenge with support assists the learner in moving from a fixed to a growth mindset (Dweck, 2008; Pajares, 1996).

One other item highlighted by the students was the human physiology requirement. Currently, the DPD curriculum does not require human anatomy and only requires human physiology. The student felt like both anatomy and physiology should be required and would be complementary to each other. Some of the students that had transferred in added that their community colleges required both and that they were able to get more out of the physiology course by having the background developed in the anatomy class. It was suggested that a hybrid course specifically designed for DPD students could be developed that covered both anatomy and physiology, especially because the material supports the curriculum in the metabolism courses.

Another challenge for DPD students is course availability, especially for introductory courses. By the time they attended orientation, many of the courses were already full when the students tried to register. The students suggested that the DPD/Department explore ways to develop lines of communication with the other departments on campus to assure enough seats are available. Beyond course closures, timing was also discussed. Many of the students work and the focus group members discussed their difficulty with scheduling classes around their work schedule.

The focus group noted advising as both a strength and an opportunity for improvement. The students recognized that the major is very competitive, but welcome discussions and professional advising by faculty about becoming successful in the field. Academic advising was especially important for navigating the biology and chemistry pre-requisites and added 
that they found the advising they received from the faculty advisors more useful than that of the college or university staff. Advising is a high-impact practice the supports student success, especially retention and persistence (Kuh et al., 2006).

When discussing opportunities, the students noted several of interest. The students would like an opportunity to get involved in additional undergraduate research with the faculty. As noted before, student-faculty interaction supports overall student success (Kuh et al., 2006; Umbach \& Wawrzynski, 2005). Undergraduate research is one opportunity to interact with faculty outside of the classroom.

Additionally, the students would like the opportunity to work with the nutrition analysis software that is used on campus. However, this is confounded by the computer lab time constraints. Practice case studies were also discussed. The students felt that these case study exercises in the curriculum were valuable and they encouraged the program to add additional opportunities for case studies in the curriculum.

Other opportunities include career readiness and networking. The students on the focus group panel desire more job interviewing preparation, practice, and "life skills" preparation. They would like the opportunity to gain interviewing practice before entering the workforce. For opportunities in networking, the students focused on the California and local Academy of Nutrition and Dietetics chapter meetings, and suggested the department hold professional networking events. Ideas such as a "Dietitian's Picnic" lunch-and-learn or a "Mini-State" conference meeting were proposed.

The focus group spent time discussing the 2024 credentialing requirement changes (Commission on Dietetic Registration, 2020). The discussion centered on the need to offer a coordinated Dietetic Internship and Master's degree program in the future.

\section{Limitations}

As with all research, this study has limitations which must be noted. First, this study was cross-sectionally conducted with a sample of students in one program, one time, at one university in California. Results for another program may be vastly different. Second, although widely recruited, the sample was entirely female, third- and fourth-year students, who were primarily older $(\lceil=27.00)$ than the average student in the program, which is just over 23 years old (CPP, 2020). The program is largely female, but male representation may provide additional insights not collected here. Additionally, as this was a focus group, the sample size was relatively small. The sample population represents only a small portion of the entire student body enrolled in the Didactic Program in Dietetics. The sample did somewhat reflect the ethnic diversity of the students in the program. However, Asian students may be underrepresented.

As with all focus groups, there may have been unknown pressure on the students to either say or not say something during the focus group session. The researcher conducting the focus group was a faculty member in the program. Although that faculty member has a positive relationship with the students, they may have felt as if they could not say something or had to 
answer differently than they normally would. Finally, as with all qualitative research, the researcher's subjective feelings could influence the outcomes of this study. This fact is true for both the focus group session and the researcher's interpretation of the results. However, the moderator tried to remain unbiased and emotionless during the session by limiting the questions to those outlined in the appendix.

There are limitations to focus group research that must be acknowledged (Smithson, 2000). Focus groups can be dominated by a single person. However, this did not occur in this group session. Additionally, there is often the tendency towards a normative discourse between the group members, which was not evident in this focus group beyond the use of professional language code (such as AND and DPD) and language typical of the campus environment. Even considering these and other potential limitations, focus groups are a beneficial way to collect opinions and information on questions of concern, needs, and suggestions for program improvement.

\section{Future Research}

There are many possibilities for future research in this area. First, this data was collected as part of assessing program strengths and weaknesses prior to a reaccreditation. The results were submitted as part of the self-study in preparation for the site visit. Additional focus groups should be conducted annually to affirm these results. Additional research can be conducted to advise the program about changes that were unseen or unmentioned in this study. Expanding the items discussed in this study to a survey instrument that can be used with the program's student body will provide broader insight with regards to the items discuss in the focus group. Additional research should be conducted to benchmark this program against other accredited didactic programs in dietetics in the United States and identify themes that may exist nationally rather than regionally at one campus. Finally, additional research can be conducted in conjunction with ACEND that can be used to inform assessment and accrediting decisions.

Qualitative research often advises a directional quantitative research. Therefore, the results of this study can be used to develop survey tools for broad applications across all the students in the program. In addition, these results can be used to revise the program's current graduating seniors exit exam and survey.

\section{Conclusion}

Focus group research allows for an intimate discussion between the researcher and the participants. This focus group examined the experiences of students enrolled in the Didactic Program in Dietetics at a large, public university in California. The students, in general, were pleased with their experiences in the program. The strengths of the program were the faculty, student body, clubs, and curriculum. However, the student focus group added that there are areas for improvement. Access to common space for gathering and studying and access to specific computer software and computer labs were noted as a weakness. Additionally, certain prerequisites can be stumbling blocks for the students. As these results were collected as part of a reaccreditation, the results can be used to advise the program's faculty and staff as they continue to assess the program and also plan for the future model of dietetics. Student success, 
retention, and persistence are important goals of the university, and the department's degree programs. These results should be utilized by the program, as well as college and university administrators, to look for opportunities to fix access issues, revise curriculum and prerequisites, and invest in faculty development; all of which will support student success and the university/program goals.

\section{References}

Accreditation Council for Education in Nutrition and Dietetics [ACEND]. (2018). ACEND accreditation standards for nutrition and dietetics Programs (DPD) [Pamphlet]. https://www.eatrightpro.org/-/media/eatrightpro-files/acend/about-program-accreditation/accr editation-standards/2017-standardsfordpdprograms.pdf?la=en\&hash=18A1A38F3236341541 8B9E72E055AC98DD0438C0

Arnold, N., Voight, M., Morales, J., Dancy, K., \& Coleman, A. (2019). Informing improvement: Recommendations for enhancing accreditor data-use to promote student success and

equity. https://vtechworks.lib.vt.edu/bitstream/handle/10919/95108/InformingImprovement.pdf?sequ ence $=1 \&$ isAllowed $=\mathrm{y}$

Astin, A. W. (1993). What matters in college?: Four critical years revisited (1st ed.). Jossey-Bass.

Bandura, A. (1993). Percieved self-efficacy in cognitive development and functioning. Educational Psychologist, 28(2), 117 - 148. https://doi.org/10.1207/s15326985ep2802_3

Barr, A. B., Walters, M. A., \& Hagan, D. W. (2002). The value of experiential education in dietetics. Journal of the American Dietetic Association, 102(10), 1458-1460. https://doi.org/10.1016/S0002-8223(02)90323-8

Brittingham, B., O'Brien, P. M., \& Alig, J. L. (2008). Accreditation and institutional research: The traditional role and new dimensions. New Directions for Higher Education, 2008(141), 69-76. https://doi.org/10.1002/he.294

Cal Poly Pomona [CPP]. (2020). Active students. Retrieved June 9 from https://analytics.cpp.edu/\#/site/production/views/ActiveStudentReportUA/ActiveStudents?:ii $\mathrm{d}=1$

Chemers, M. M., Hu, L., \& Garcia, B. F. (2001). Academic self-efficacy and first-year college student performance and adjustment. Journal of Educational Psychology, 93(1), 55-64. https://doi.org/10.1037/0022-0663.93.1.55

Commission on Dietetic Registration. (2020). 2024 Graduate degree requirement Registration eligibity Commission on Dietetic Registration. https://www.cdrnet.org/graduatedegree

Creswell, J. W. (2005). Educational research: Planning, conducting, and evaluating quantitative and qualitative research (2nd ed.). Merrill. 
Creswell, J. W. (2007). Qualitative inquiry \& research design: Choosing among five approaches (2nd ed.). Sage Publications. http://www.loc.gov/catdir/enhancements/fy0701/2006031956-d.html

Dweck, C. S. (2008). Mindset: The new psychology of success (Ballantine Books trade pbk. ed.). Ballantine Books.

Edens, D. (2012). The value of student satisfaction assessment at for-profit higher education institutions.

https://www.noellevitz.com/papers-research-higher-education/2012/student-satisfaction-resea rch-on-career-and-for-profit-colleges

Elliot, K. M., \& Shin, D. (2002). Student satisfaction: An alternative approach to assessing this important concept. Journal of Higher Education Policy and Management, 24(2), 197-209. https://doi.org/10.1080/1360080022000013518

Helms Marilyn, M., \& Nixon, J. (2010). Exploring SWOT analysis - where are we now? A review of academic research from the last decade. Journal of Strategy and Management, 3(3), 215-251. https://doi.org/10.1108/17554251011064837

Kessler, L. A., \& Burns-Whitmore, B. (2011). Student perceptions of reflection tools used in a service learning community nutrition course. NACTA Journal, 55(3), 67-69. www.jstor.org/stable/nactajournal.55.3.67

Kessler, L. A., Burns-Whitmore, B., \& Wallace, S. P. (2010). Focus groups reveal dietetic students' opinions on the addition of cultural competency training to the dietetics curriculum. NACTA Journal, 54(4), 2-6. www.jstor.org/stable/nactajournal.54.4.2

Kessler, L. A., Burns-Whitmore, B., Wallace, S., \& Lewis, D. (2009). Focus groups reveal dietetic students' opinions on cultural competence and the proposed addition of a Hispanic-focused dietetic training program. Journal of Nutrition Education and Behavior, 41(4), S30. https://doi.org/10.1016/j.jneb.2009.03.026

Kessler, L. A., Wallace, S., Gordon, A., Moran, M., \& Burns-Whitmore, B. (2013). Evaluation of Estudiante de Dietetico: A Spanish curriculum for dietetic undergraduates. Journal of the Academy of Nutrition and Dietetics, 113(9), A52. https://doi.org/10.1016/j.jand.2013.06.179

Kuh, G. D., Kinzie, J., Buckley, J. A., Bridges, B. K., \& Hayek, J. C. (2006). What matters to student success: A review of the literature. http://citeseerx.ist.psu.edu/viewdoc/download?doi=10.1.1.169.4913\&rep=rep1\&type=pdf

Kuh, G. D., Kinzie, J., Schuh, J. H., Whitt, E. J., \& Associates. (2005). Student success in college: Creating conditions that matter. Jossey-Bass.

Lubinescu, E. S., Ratcliff, J. L., \& Gaffney, M. A. (2001). Two continuums collide: Accreditation and assessment. New Directions for Higher Education, 2001(113), 5-21. https://doi.org/10.1002/he.1

Massa, L. J., \& Kasimatis, M. (2017). Meaningful and manageable program assessment: A how-to guide for higher education faculty. Stylus Publishing, LLC. 
Olivares, L., Burns-Whitmore, B., \& Kessler, L. (2015). Retaining Hispanic dietetic undergraduate students through mentoring and professional development. Journal of the Academy of Nutrition and Dietetics, 115(5), S10-S15. https://doi.org/10.1016/j.jand.2015.02.023

Pajares, F. (1996). Self-efficacy beliefs in academic settings. Review of Educational Research, 66(4), 543-578. https://doi.org/10.3102/00346543066004543

Parker, A., \& Tritter, J. (2006). Focus group method and methodology: Current practice and recent debate. International Journal of Research \& Method in Education, 29(1), 23-37. https://doi.org/10.1080/01406720500537304

Pintrich, P. R. (2004). A conceptual framework for assessing motivation and self-regulated learning in college students. Educational Psychology Review, 16(4), 385-407. https://doi.org/10.1007/s10648-004-0006-X

Pollard, P., Taylor, M., \& Daher, N. (2007). Gender-based wage differentials among registered dietitians. The Health Care Manager, 26(1). https://doi.org/10.1097/00126450-200701000-00007

Schunk, D. H. (1991). Self-efficacy and academic motivation. Educational Psychology, 26(3 \& 4), 207-231. https://doi.org/10.1080/00461520.1991.9653133

Smithson, J. (2000). Using and analysing focus groups: Limitations and possibilities. International Journal of Social Research Methodology, 3(2), 103-119. https://doi.org/10.1080/136455700405172

Svinicki, M. (2004). Learning and motivation in the postsecondary classroom. Jossey-Bass.

Umbach, P. D., \& Wawrzynski, M. R. (2005). Faculty do matter: The role of college faculty in student learning and engagement. Research in Higher Education, 46(2), 153-184. https://doi.org/10.1007/s11162-004-1598-1

Wiers-Jenssen, J., Stensaker, B., \& Grogaard, J. B. (2002). Student satisfaction: Towards and empirical deconstruction of the concept. Quality in Higher Education, 8(2), 183-195. https://doi.org/10.1080/1353832022000004377

Wynn, C. L., Raj, S., Tyus, F., Greer, Y. D., Batheja, R. K., Rizwana, Z., \& Hand, R. K. (2017). Barriers to and facilitators of dietetics education among students of diverse backgrounds: Results of a survey. Journal of the Academy of Nutrition and Dietetics, 117(3), 449-468. https://doi.org/10.1016/j.jand.2016.06.010

\section{Copyright Disclaimer}

Copyright for this article is retained by the author(s), with first publication rights granted to the journal.

This is an open-access article distributed under the terms and conditions of the Creative Commons Attribution license (http://creativecommons.org/licenses/by/4.0/). 